\title{
Real-Time Concept Feedback in Lectures for Botho University Students
}

\author{
Alpheus Wanano Mogwe \\ Library \& Information Studies | Faculty of Computing \\ University of Botswana | Botho University \\ Gaborone, Botswana
}

\begin{abstract}
This is a mixed methodology study which focused on developing a real-time concept feedback system for Botho University students. The study takes advantage of the tablets distributed freely by the institution to ameliorate the problem of lack of understanding of module concepts during lecture lessons. The system addresses issues of providing real-time feedback as the lecture is ongoing without disturbing other students, thus upholding effective class participation and interaction without the need of voicing own concerns loud to the lecturer, and in turn the lecturer is able to view the students' interactions and address them. The real-time concept feedback system was used to test student comprehension of concepts, improve participation, engagement and attendance. The study identified many factors affecting students' participation and interaction in a traditional class which inhibits understanding of concepts; hence, the development of the application to address such. It concluded that real-time concept feedback systems are vital in addressing students understanding in lecture sessions, thus upholding the importance of ICTs in education.
\end{abstract}

Keywords-Real-time feedback systems; interactive technology; e-learning; information technology; understanding of concepts

\section{INTRODUCTION}

With Information and Communication Technologies (ICTs) having strong repercussions in the education and learning sector around the world, Botho University has become the first institution in Botswana to provide free tablets for learning and bridge the digital gap between its students. In a knowledge based economy, education is a requirement and in this modern era it comes with need for knowledge and interaction with ICTs as envisioned through the efforts of Botho University of providing a free tablet to each and every Botho student, a gesture which goes a long to facilitate the teaching and learning process. This is so, because ICTs are exceptionally a commanding tool for information and knowledge diffusion the primary characteristic of the whole education course. Therefore, ICTs play a pedagogic duty complementing the traditional delivery of education and learning.

With these tablets, the e-learning environment has been improved and brought to higher standards as all the students in the campus own a tablet, are able to access online resources including online databases, repositories and books. This has made learning easier, and led to this mixed methodology research to measure students' understanding in a class set up using their own tablets whilst interacting with a mobile web application developed to address their concerns.
The study identified a major problem of lack of understanding of concepts during class sessions during an ongoing lecture. This is compounded by lack of interaction from other students who would have not understood the lecture concepts but carry on for some various reasons such as being shy to participate in the midst of others or the traditional mode of delivery itself [1] where the lecturer would call for volunteers or handpick own choice of students. Moreover, lack of immediate feedback whenever they fail to understand concepts, as feedback is a key component to successful learning [2], [3] attributes to the same problem. This leads to lack of understanding which eventually leads to failure. Thus, the study sought to understand how real time concept feedback in lectures could be incorporated in the learning environment of Botho University using the already available tablets devices to ameliorate the lack of understanding which happens during lecture sessions whilst being inclusive of all students irrespective of them being fast or slow learners in their comfort zones-seats. The research question of the study was "How can understanding of concepts in a class be improved in real time?"

The study focused on the following objectives to drive the main purpose identified above:

- To analyse students understanding of concepts in a lecture session and how they communicate their understanding or lack of understanding.

- To establish students participation and interaction in a lecture session and how it affects understanding of concepts in a lecture.

- To ascertain students behaviour when they fail to understand concepts taught during a class or lecture session and how that impacts on the rest of the lecture and module coverage.

- To identify real-time concept feedback systems with intent on understanding their operations, strengths and weaknesses for aid in development of a real time concept feedback system.

Through these objectives, a clear understanding of various characteristics related to students, learning, teaching and understanding of concepts in a lecture session was articulated to fully address the main problem of lack of understanding in a class and how real time concept feedback in lectures could be incorporated in the learning environment. This is important before considering how real time concept feedback systems could actually revolutionize the learning environment as 
education is not a field which easily lends itself to experimentation but works on a codified manner. Therefore, a further analysis of this subject area was supplemented through secondary research involving various literatures on the same.

\section{LITERATURE REVIEW}

Education delivery is a foundation of teaching and learning. It is more than coming into a class and start talking, but an intricate situation involving the lecturer (instructor) and the learners (students). One factor attributing to the complexity of teaching and learning is the different paces of learning in each and every student and charging through a syllabus disregarding those paces and students diversity in learning is a peril recipe for students' failure both in terms of assessment and learning outcomes [1], [4]. And this is due to understanding of the concepts being taught in a class or lecture session. Due to the diversity of students' paces in learning, their understanding tends to vary as others would be fast learners whilst others are slow or moderate learners, which could be a misled point to the lecturer or instructor to believe majority understand or do not understand [1].

Understanding of this concepts becomes key for them to navigate through the whole lecture session which either leads to participation, interactivity and a sense of belonging or vice versa of all the mentioned. Therefore, real-time feedback is a key to achieving the positive of that. Without receiving regular and real time feedback, it becomes difficult for them to understand and or comprehend materials being taught [5]. Various authors have attributed that real-time feedback is an important aspect in the learning environment as it helps the instructors to be more responsive to learners and assist them in a timely manner [2] not only to notice shortfalls of the students after the assessment component [4].

\section{A. Personalizing Learning for Real-Time Feedback}

One way to achieve real-time feedback is being able to personalize learning for each and every student to address their pace diversity. The moment a lecturer steps into a class environment and start the lecture session, he or she is inundated with a lot of questions, and those are mostly related to (1) Are the students understanding the lecture (2) Are the concepts clearly modularized for clear understanding (3) Is the lecture relatable. All these questions are only answered through students' feedback and in traditional delivery mode, no emphasize is per individual student but generalization is employed. Thus, a majority affirmative response paves the way for the lecturer to continue teaching [1], [4] whilst ignoring the silent pleas of those who would have not understood but shied away to voice their concerns due to various reasons.

This in turn affects the lecture or the overall module or subject area, though timely feedback may be incorporated later to understand how they are doing in the subject. Timely feedback becomes a problem as it wouldn't be carried often thus the gap left to be addressed through the use of real time feedback. With students having tablets in Botho University, real-time feedback systems become a favorable option to personalize learning for students. With real time feedback systems, such concerns are addressed as students interact with systems individually thus able to voice out concerns without being muzzled by the voice of many. According to Cialdini (2008), anonymity is one aspect which students want to maintain as a way of not embarrassing themselves and it gives them confidence to introspect own level of understanding without fear or any form of victimization learning [2].

\section{B. Real-Time Feedback Systems Enhances Students Self- Regulation Skills}

Sitzmann et al. [5] stipulates that real-time feedback systems enhance students' self-regulation skills. Students are in a better position to learn how to evaluate their own learning, thus being able to gauge if they are on the right track and have a good understanding of the concepts being taught, thus influencing their behaviour [6], [7]. Unlike, having to wait for consultation after class, which many students hardly do, utilising real-time feedback systems gives students a sense of control over their learning during the lecture and empowers them to silently query the lecturer whenever they get lost in understanding of the concepts.

In addition to evaluating their own understanding, this also helps to evaluate the lecturers' teaching and delivery mode in real time, and both the students and lecturer can quickly make amends or appropriate changes whenever they were off track in either understanding or delivering the concept. On the course of enhancing the self-regulation skills, the relationship between the lecturer and the students is strengthened for the benefit of the students to understand the learning material instead of having lackluster assessments or disappointing results at the end [1]. Thus, with real-time feedback systems a clearer idea of student understanding is captured well in time and this improves their self-regulation skills.

\section{Real-Time Feedback Systems Increase Students Classroom Presence}

Real-time feedback systems increase students' classroom presence, interaction and participation [8], [9]. With students noting that their needs are being addressed, their attendance also improves and builds the confidence of interaction and participation in the class [10]. Authors in [11], [12] notes the importance of personalised response systems and diverse learning styles in education and how this affects their engagements in class, attendance, motivation and participation in a class [13]. Through this online feedback, information needed to improve certain areas would be addressed whilst assisting in improving learners' motivation and learners' ability to reflect on own learning. Moreover, increased classroom presence, interaction and participation would lead to increased student performance. Studies have indicated that real-time feedback systems also improve student performance although they fail to identify the causes of such improvements [2], [14].

\section{METHODOLOGY}

The research study followed a mixed methodology approach. Understanding of concepts during teaching and learning is one area which hasn't been well explored within the Botho University environment, and the author sought to understand how this could be addressed and how real-time concept feedback in lectures for Botho University Students could be utilised to ameliorate the understanding of concepts in class sessions. The research was conducted within the Botho 
University environment with questionnaires distributed and interviews done on selected individuals.

The mixed methodology approach was selected as the best approach to understand fully and in-depth on this area and offer conclusive analysis and suggested solutions to the identified problem of students failing to understand learning concepts during class and how this situation can be mitigated through the use of real time concept feedback systems in lectures. Exploring this untapped area would increase awareness of shortfalls of timely feedback versus real-time feedback whilst determining the cause nature of the problem and possible ways which can be utilised to solve the problem [15]. A mixed methodology approach helps understand the situation from all angles for better conclusions [16]. This then, forms the basis of the conclusive research, with alternative solutions [17]-[19].

Population for the study and sampling procedure are also important. The population of this study was made up of student and lecturers of Botho University. A population of study is important to validate the target audience, and Burns and Grove [20] defines a population as all elements inclusive of objects, individuals and events that meet the sample criteria for inclusion in a study. A questionnaire was distributed to 30 students. The questionnaire administration and data gathering followed the Exponential discriminative snowball sampling technique.

\section{RESULTS}

The purpose of the study was to assess how understanding of concepts in a class can be improved in real-time, as lack of understanding of concepts during ongoing lecture sessions was identified. It sought to understand how real time concept feedback systems in lectures could be incorporated in the learning environment of Botho University using the already available tablets devices to ameliorate the lack of understanding which happens during lecture sessions. To do that, it was imperative to carry a questionnaire data gathering to understand the students and their understanding capabilities and behaviours and conduct interviews on selected individuals. This questionnaire was administered following the exponential discriminative snowball sampling technique, where a subject identified would attempt the questionnaire and refer multiple referrals to do the same too. A selection of the subjects who met the aim and objectives of the study would then follow, and interviews would be conducted on few selected to iron out inconsistencies. The following is the results of the study summarized as per the study objectives.

\section{A. Objective 1: To analyse students understanding of concepts in a lecture session and how they communicate their understanding or lack of understanding.}

1) Understanding of Concepts: This question sought to understand if students easily understood concepts in a lecture session.

From Fig. 1 (refer to appendix) it can be noted that $20 \%$ of the respondents indicate they always understand concepts when taught, whilst $37 \%$ indicate that sometimes they do understand the concepts, $27 \%$ indicate that they rarely understand concepts with $13 \%$ saying they never understand and $3 \%$ noting that they don't know if they understand concepts or not. This indicates a similar pattern identified during various studies that understanding of concepts by students varies [1], [4] and to comprehend materials taught becomes difficult if understanding of concepts is lacking [5].

\section{2) Relating Concepts Understanding to Learning} Outcomes: The question sought to understand if respondents would relate understanding of concepts during lecture session to learning outcomes of the module.

Respondents at $30 \%$ indicated that they are able to relate concepts to learning outcomes whilst the other $30 \%$ noted that sometimes they do relate the two. $33 \%$ noted that they rarely relate learning concepts to learning outcomes and $7 \%$ said they never relate the two. For those who never relate the two, the issue could be tied to lack of comprehension of the concepts, thus making it difficult to follow on the concepts taught and relating [5]. Refer to Fig. 2 in appendix.

3) Do you communicate lack of Understanding: the question sought to understand I students do voice out their concerns when they do not understand any concepts during a lesson.

The results indicate that $33 \%$ communicate their lack of understanding of concepts with $10 \%$ noting that sometimes they do. $40 \%$ of respondents noted that they rarely communicate their lack of understanding and $17 \%$ never do so. This shows that only few students are able to communicate whenever they understand or do not understand, whilst majority do not communicate (refer to Fig. 3 in appendix) and this could be attributed to the traditional mode of delivery which is rigid as attributed by Caldwell [1].

\section{4) What Holds Communication Amongst Learners}

Fig. 4 in appendix indicates ccommunication is vital to get feedback, and $30 \%$ of respondents noted that they are freespirit respondents who always communicate their lack of understanding, whilst other respondents noted that they are various factors which holds them from communicating their lack of understanding ranging from uncertainty of whether to communicate at $20 \%$, others are naturally quite at $7 \%$ and shyness was blamed for lack of communication at $43 \%$. According to Cialdin (2008), many factors contribute to students remaining silent on communicating whenever they do not understand, similar conclusion reached by other authors [1], [2] and [4].

\section{B. Objective 2: To establish students' participation and interaction in a lecture session and how it affects understanding of concepts in a lecture.}

\section{1) Do You Normally Participate in a Class?}

Respondents as indicated in Fig. 5 (refer to appendix) they do participate in a class at $43 \%$, with $17 \%$ saying sometimes they participate and $37 \%$ noting that they rarely participate and $3 \%$ saying don't participate in a class. Lack of participation has been found to be a major setback of making students to easily understand concepts and this could be attributed to the traditional model itself [1], [3] and lack of technology to promote inclusiveness policy for all students where anonymity would be upheld [2]. 
2) Do You Interact with Other Learners and Your Lecturer?

Many learners indicate at $50 \%$ that they do interact with other learners and the lecturer in a class, with $10 \%$ noting that sometimes they do participate and $40 \%$ saying they rarely participate. Interaction is a vital tool in accessing feedback and lack of it impacts negatively in understanding of concepts and getting relevant feedback [5] as indicated in Fig. 6 in appendix.

3) Does Participation and Interaction Influence you Understanding?

Respondents agree at $40 \%$ that participation and interaction influences understanding of concepts in a class, with $30 \%$ saying sometimes this two attributes could influence understanding of the concepts whilst $13 \%$ say this two rarely influence. $17 \%$ of the respondents noted that they don't know if these two attributes influence understanding of concepts (refer to Fig. 7 for full results) Self-regulation is one aspect which has been touted to be improved through the use of realtime feedback systems, and this is attributed to participation and interaction [6], [7]. From Fig. 7 it shows that lack of such systems impacts negatively to student self-regulation.

\section{Objective 3: To ascertain students behaviour when they fail to understand concepts taught during a class or lecture session and how that impacts on the rest of the lecture and module coverage.}

1) What happens when you fail to understand lecture concepts \& outcomes? The question sought to understand the behaviour of students in relation to lack of understanding concepts during a lecture session.

It was noted that the traditional mode of delivery has come as a muzzling approach to slow learners which leads to them not to communicate or participate when not understanding [1] [4], thus this in a way influences the behaviour exhibited by student when they fail to understand concepts, as indicated in Fig. 8. At $23 \%$, respondents noted that they get motivated to further ask questions whenever they fail to understand concepts, whilst $30 \%$ indicated the opposite. $23 \%$ of the respondents noted that they ask their fellow students whilst $13 \%$ ask the lecturer and $10 \%$ noted that they just don't do anything. All the behaviours exhibited here are linked to the diversity of paces in learning, as more vocal and fast learners are able to exhibit behaviours of asking in a class and not giving up [1].

2) How that does impacts your whole lecture and module? Upon understanding how students behave whenever they don't understand concepts, it was also relevant to appreciate how their actions on the previous question impact their whole lecture session and consequently the module area.

Lack of understanding can have a negative impact on a student during the lecture, or an overall negative impact on the module itself. This is only possible to be noticed at the timely feedback intervals which sometimes fall after assessments [1] [4] thus not being real time and becomes difficult to amend and correct. $37 \%$ of the respondents as indicated in Fig. 9, noted that they try by all means to understand whilst $30 \%$ never gives up on understanding the concepts. $20 \%$ of the respondents noted that they give up, with $13 \%$ noting that sometimes they do give up. It is within the groups that try to understand including those who give up that concentration needs to be channeled to and introduce other forms which could help bridge the understanding gap, and real-time concept feedback systems become handy for utilisation.

\section{CONCLUSION}

The study, as indicated by the literature review and the students themselves, concluded that understanding of concepts is clearly a problem amongst students. This lack of understanding of concepts during lecture sessions is further compounded by the traditional way of delivery which constrains students and hampers them to communicate their lack of understanding. Participation and interaction during classes have also been found to be low in many students, which also contribute to lack of understanding. The students' behaviour is also a contributing factor as students easily give up on following whenever they are not understanding due to the systems in place which centralizes mostly onto the traditional approach of delivery, thus need of timely diagnostic feedback concept systems which students have come to appreciate [21], [22].

The researcher concluded that a real-time concept feedback system is essential in the Botho University environment as the technology is available for utilisation. Real-time feedback is paramount in learning, as students can easily track their learning and provide feedback in real-time for more clarifications when they fail to understand. The researcher concluded by developing the real-time concept feedback application, but due to time constraints, on writing of the findings it has not been

- Piloted to test the students perceptions on the utilisation of the product.

- Piloted to test the lecturers on the utilisation of the same.

- It has not been fully tested and evaluated how it measures to address the gap identified during the problem statement.

The researcher concludes that more work needs to be done on this area and alternative ways found to be utilised to address the issue of understanding in class, with the aid of using realtime concept feedback systems both for the benefit of the lecturer and the students.

\section{ACKNOWLEDGMENT}

The researcher thanks all the Botho University community and participants of the study.

\section{REFERENCES}

[1] Caldwell, J. (2007). Clickers in the Large Classroom: Current Research and Best-Practice Tips. Life Sciences Education, 6, 9-20.

[2] Hedgcock, W.H and Rouwenhorst, R.M. (2014). Clicking their way to success: using student response systems as a tool for feedback. Journal for Advancement of Marketing Education, Volume 22, Issue 2, Fall 2014

[3] Martin, Florence, James Klein, and Howard Sullivan (2007), "The Impact of Instructional Elements in Computer -Based Instruction," British Journal of Educational Technology , 38(4), 623-36.Cialdini, Robert B.(2008),Influence: Science and Practice,New York: Pearson 
[4] Sun, L., "The Use of a Real Time Online Class Response System to Enhance Classroom Learning," ASEE Engineering Design Graphics Division - 69th Midyear Conference, Normal, IL, October 12-14, 2014.

[5] Sitzmann, Traci, Katherine Ely, Kenneth G. Brown,and Kristina N. Bauer (2010), "Self-Assessment of Knowledge: A Cognitive Learning or Affective Measure?"Academy of Management Learning \& Education, 9(2),169-191.

[6] Edens, K. M. (2009). The interaction of pedagogical approach, gender, self-regulation, and goal orientation using student response system technology.Journal of Research on Technology in Education, 41(2), 161- 177.

[7] Carver, Charles S.,and Michael F.Scheier(2000), "Scaling Back Goals and Recalibration of the Affect System are Processes in Normal Adaptive Self-Regulation: Understanding 'Response Shift' Phenomena,"Social Science \& Medicine, 50,1715-1722.

[8] Ivo, N., Mitko, Z., Dragan, B. and Thanos, H., "Designing a Mobile Clicker System for Educational Purposes". 2013. The 9th International Scientific Conference.

[9] Stowell, Jeffrey R., and Jason M. Nelson (2007), “Benefits of Electronic Audience Response Systems on Student Participation, Learning, and Emotion ,"Teaching of Psychology, 34,253-58.

[10] Siau, K., Sheng, H., and Nah, F. (2006). Use of a Classroom Response System to Enhance Classroom Interactivity. IEEE Transactions on Education, 49(3), 398-403.

[11] Gauci, S. A., Dantas, A. M., Williams, D.A., \& Kemm, R.E. (2009). Promoting student-centered learning in lectures with a personal response system. Advances in Physiological Education, 33, 60-71

[12] Bajraktarevic, N., Hall, W., \& Fullick, P. (2003). Incorporating learning styles in hypermedia environment: Empirical evaluation. In P. de Bra, H.
C. Davis, J. Kay, \& M. Schraefel (Eds.), Proceedings of the workshop on adaptive hypermedia and adaptive web-based systems (pp. 41-52). Nottingham, UK: Eindhoven University.

[13] Tietz, Wendy (2005), "Using Student Response Systems to More Fully Engage Your Students," paper presented at the Colloquium on change in Accounting Education, Long Beach, California, October 26-29.

[14] Fies, C. \& Marshall, J. (2006). Classroom Response Systems: A Review of the Literature, Journal of Science Education and Technology, 15 (1), 101-109.

[15] Saunders, M., Lewis, P. \& Thornhill, A. (2012) "Research Methods for Business Students" 6th edition, Pearson Education Limited

[16] Brown, R.B. (2006) "Doing Your Dissertation in Business and Management: The Reality of Research and Writing" Sage Publications, p.43

[17] Singh, K. (2007) "Quantitative Social Research Methods" SAGE Publications, p.64

[18] Sandhusen, R.L. (2000) "Marketing” Barrons

[19] Nargundkar, R. (2008) "Marketing Research: Text and Cases" 3rd edition, p.38

[20] Burns, N., \& Grove, S. K. (1993). The practice of nursing research. Boston: Elsevier Health Sciences

[21] Lin, J.-W., Lai, Y.-C., \& Chuang, Y.-S. (2013). Timely Diagnostic Feedback for Database Concept Learning. Educational Technology \& Society. 16. (2), 228-242. 228

[22] Parvez, Shahida M..A pedagogical framework for integrating individual learning style into an intelligent tutoring system. ProQuest Dissertations Publishing, 2008.

\section{APPENDIX}

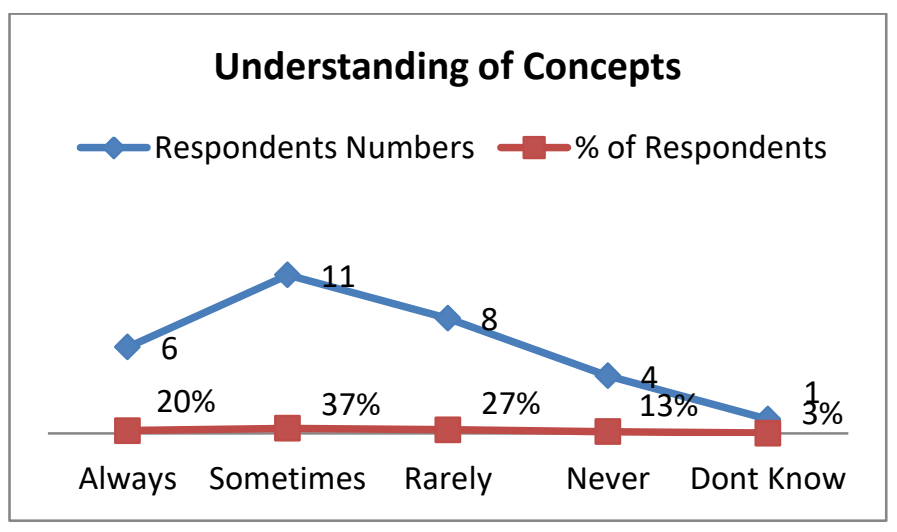

Fig. 1. Understanding of concepts.

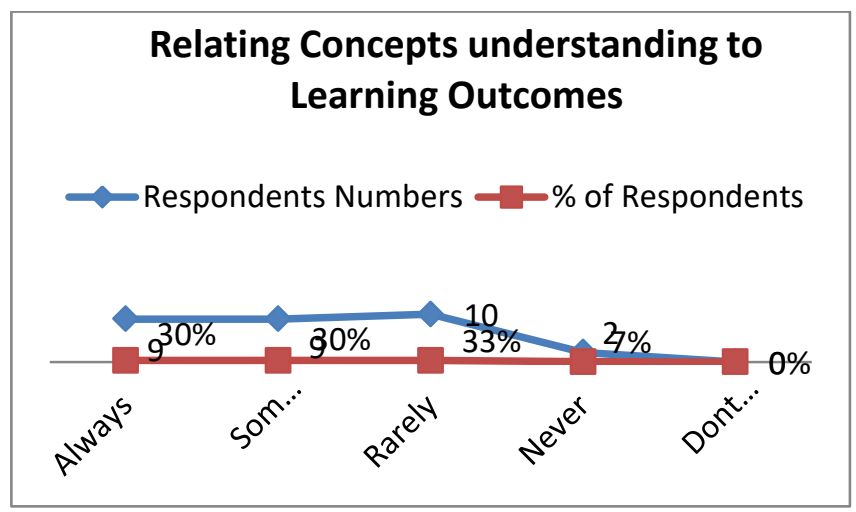

Fig. 2. Relating concepts understanding to learning outcomes.

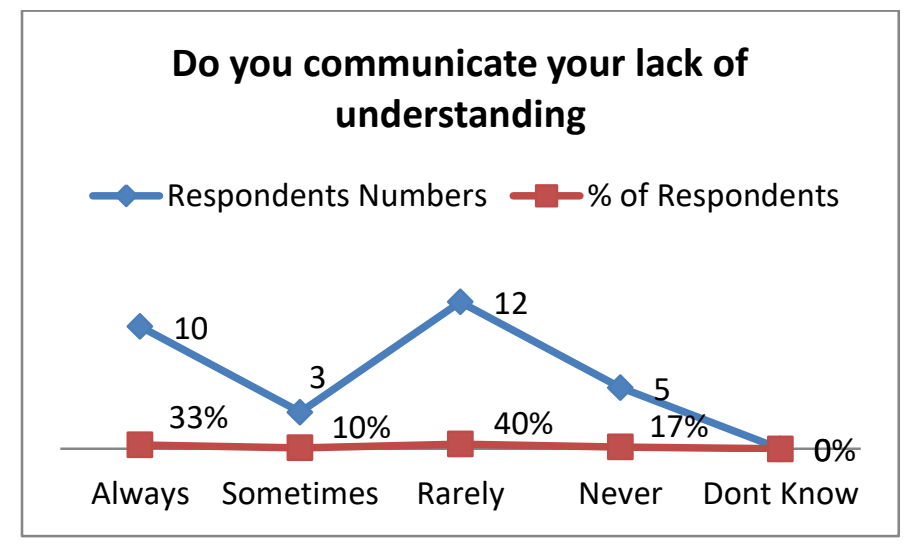

Fig. 3. Communication of lack of understanding.

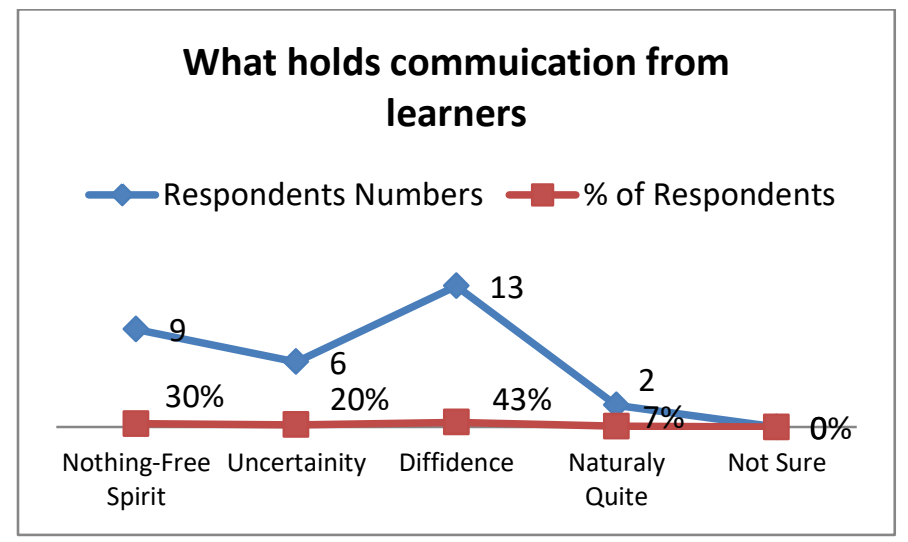

Fig. 4. Factors holding learners from communicating. 


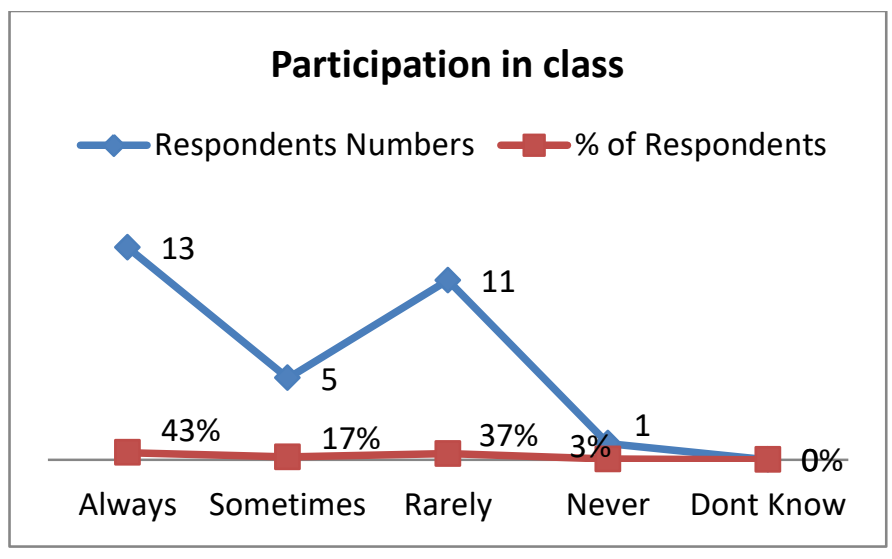

Fig. 5. Participation in class.

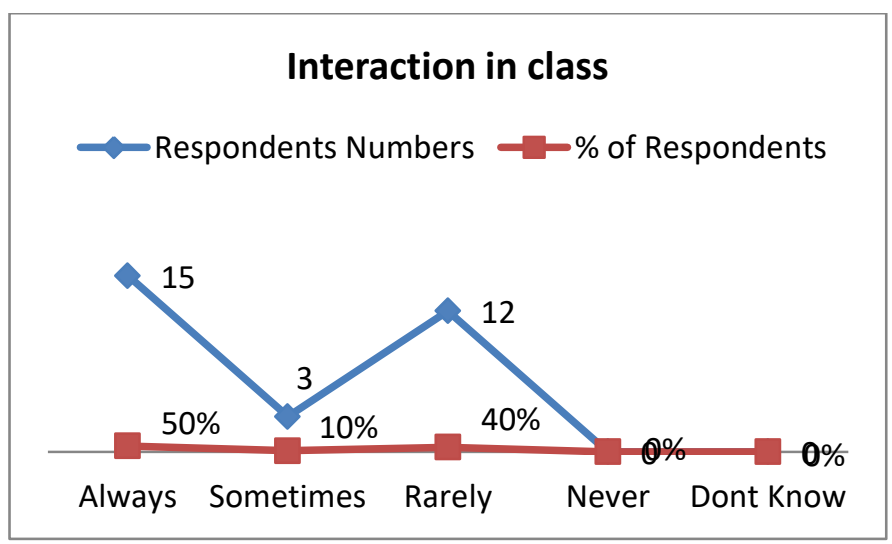

Fig. 6. Interaction in class.

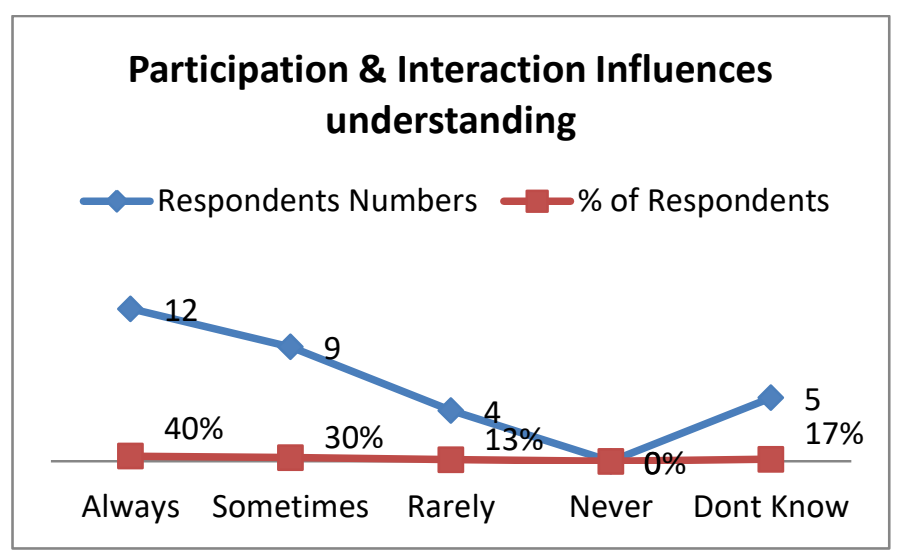

Fig. 7. Participation \& interaction influences understanding.

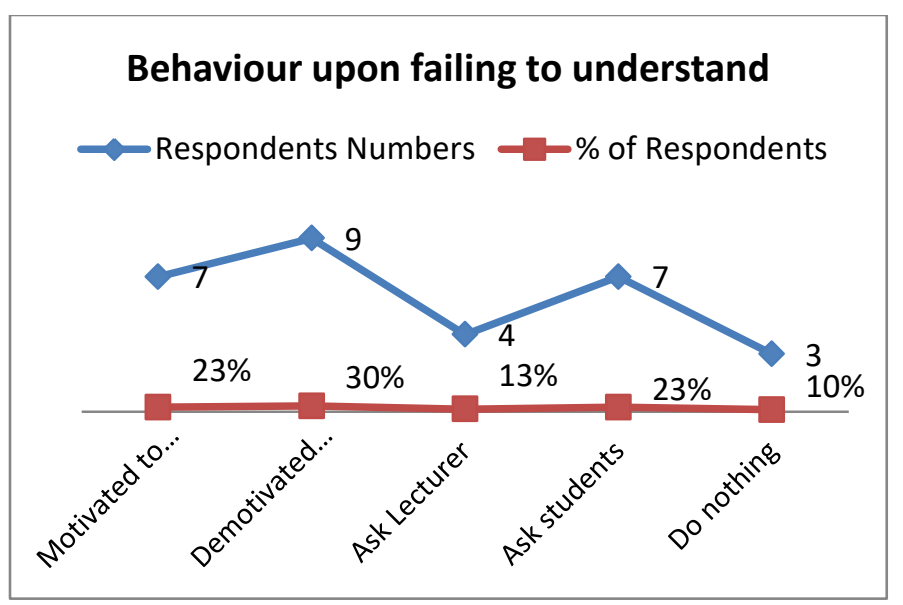

Fig. 8. Behaviour upon failing to understand.

\section{Impact of lack of understanding on the lecture/module}

$\longrightarrow$ Respondents Numbers $\quad-\%$ of Respondents
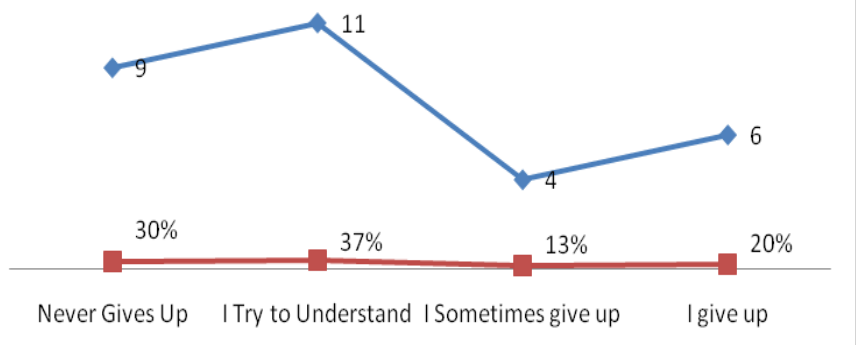

Fig. 9. Lack of understanding Impact on lecture/module. 